\title{
Cu-Mediated Syntheses of N-Fused and Ring-Modified Trithiahexaphyrins
}

\author{
Chen-Hsiung Hung, ${ }^{[a]}$ Jing-Ping Jong, ${ }^{[a]}$ Mu-Yih Ho, ${ }^{[a]}$ Gene-Hsiang Lee ${ }^{[b]}$ and \\ Shie-Ming Peng ${ }^{[c]}$
}

\begin{abstract}
The reaction of the antiaromatic [28]trithiahexaphyrin (TTHP) with $\mathrm{Cu}^{\mathrm{I}}$ in $\mathrm{DMF}$ gives a novel fusedring trithiahexaphyrin with the elimination of a chloride on a dichlorophenyl ring and bond formation to the outward oriented pyrrolic nitrogen to form a 5,5,6-tricyclic internal ring system. The NMR spectra, which display characteristics of an antiaromatic compound, agree with the proposed structure.
\end{abstract}

Meanwhile, reactions of TTHP with amines in the presence of $\mathrm{Cu}^{\mathrm{I}}$ give amino-group-inserted hexaphyrins with the amino nitrogen joined to a $\beta$-thiophenic carbon and the $\alpha$-carbon of the alkylamine cyclized to the inward pyr-

Keywords: annulenes • aromaticity - cyclization $\cdot$ heterocycles porphyrinoids rolic nitrogen to form a 5,7,5-tricyclic rings. The crystal structure of the fusedring product indicates a rectangular geometry with a tilted tricyclic ring system, while the ring-modified TTHPDMA complex gives a triangular trithiahexaphyrin core. This report demonstrates methods to incorporate functionalized heterocyclic rings into expanded porphyrins.

\section{Introduction}

Expanded porphyrins have attracted substantial attention in recent years owing to their distinctive physical properties and potential applications. ${ }^{[1]}$ As an example, sapphyrin, a wellstudied contracted/expanded porphyrin consisting of five pyrrole rings and four meso carbons, is established as a unique metal chelating ligand ${ }^{[2]}$ as well as an anion or neutral substrate receptor. ${ }^{[3]}$ Additional studies on sapphyrin - oligonucleotide conjugates show sequence-specific DNA photomodifying activity. ${ }^{[4]}$ Rapid progress has been further inspired by recent discoveries of diverse applications of expanded porphyrins as anion carriers, ${ }^{[5]}$ photodynamic therapy (PDT) sensitizers $^{[6]}$ and magnetic resonance imaging (MRI) contrast agents. ${ }^{[7]}$

Core-modified expanded porphyrins can be prepared from the acid-catalyzed condensation of 16-oxotripyrrane, 16thiatripyrrane, or 16-selenatripyrrane. ${ }^{[8]}$ In addition, 2,5bis(arylhydroxymethyl)heterocyclopentadienes have been

[a] Prof. C.-H. Hung, J.-P. Jong, M.-Y. Ho

Department of Chemistry

National Changhua University of Education

Changhua, 50058 (Taiwan)

Fax: $(+886) 4-7211190$

E-mail: chhung@cc.ncue.edu.tw

[b] G.-H. Lee

Instrumentation Center

National Taiwan University, Taipei (Taiwan)

[c] Prof. S.-M. Peng

Department of Chemistry

National Taiwan University, Taipei (Taiwan) used as building blocks for the preparation of core-modified porphyrins. A variety of 21,23-diheteroporphyrins with pyrrolic nitrogen atoms replaced by oxygen, ${ }^{[9]}$ sulfur, ${ }^{[10]}$ or selenium $^{[11]}$ atoms have been prepared from the acid-catalyzed condensation. Core-modified expanded porphyrins such as 26,28-dioxasapphyrin and 26,28-dithiasapphyrin can also be isolated from the condensation of pyrrole, arylaldehyde, and 2,5-bis(arylhydroxymethyl)furan or 2,5-bis(arylhydroxymethyl)thiophene. ${ }^{[12]}$ Recently, the isolation of tetrathiaoctaphyrin and dihydrotetrathiaoctaphyrin from the acid-catalyzed condensation of pyrrole and 2,5-bis(arylhydroxymethyl)thiophene reported by Latos-Grażyñski ${ }^{[13]}$ and the isolation of trithiahexaphyrins in our group $^{[14]}$ established a routine method for the access of aryl-substituted core-modified expanded porphyrins. Importantly, various porphyrins with different ring size and aromaticity can be obtained from this method.

Few reports are available for the post-porphyrin-ring modification. Verdoheme, an 5-oxaporphyrin, synthesized by coupled oxidation has been used to demonstrate heme degradation. ${ }^{[15]}$ An early report by Sessler showed a nucleophilic attack of methoxy group at a meso-position of the uranyl sapphyrin complex. ${ }^{[16]}$ A recent report demonstrated that nucleophilic meso-addition proceeded cleanly and selectively on diminished $\pi$ system in tetraphenylbenziporphyrin. ${ }^{[17]}$ The last two examples suggest the correlation of postporphyrin-ring modification with the electron density on porphyrin conjugate system. From the study of $\mathrm{N}$-confused porphyrin, the first ring-modified porphyrin analogue, ${ }^{[18]}$ $\mathrm{N}$-fused porphyrin (NFP) was discovered. Most recently, the 
<smiles>C1=CC(=C(c2ccc(C(c3ccccc3)=c3ccc(=C(c4ccccc4)c4ccccc4)[nH]3)[nH]2)c2ccc(-c3ccccc3)[nH]2)CC1=C(c1ccccc1)c1ccccc1</smiles>

NCP

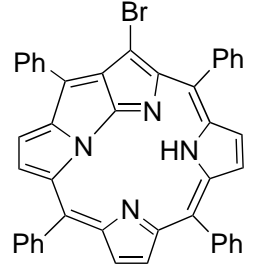

NFP

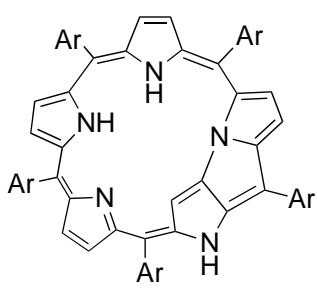

$\mathrm{NFP}_{5}$
$\mathrm{N}$-fused pentaphyrin $\left(\mathrm{NFP}_{5}\right)$ was isolated from the normal Rothemund-type condensation of pyrrole and pentafluorobenzaldehyde following by a 2,3-dichloro-5,6-dicyano-1,4benzoquinone (DDQ) oxidation. ${ }^{[19]}$ The available fused-ring products suggest that porphyrin-ring modification is common for relatively flexible porphyrin systems. Although the flexibility of porphyrin rings and the aromaticity appear to be important factors for porphyrin-ring-modification reactions, there is no systematic study on the reaction conditions for the preparation of ring-modified porphyrins. As an extension of our work on trithiahexaphyrin, herein we report the use of antiaromatic hexakis(2,6-dichlorophenyl)-32,34,36trithiahexaphyrin-(1.1.1.1.1.1) as starting material to prepare a $\mathrm{N}$-fused trithiahexaphyrin with a unique 5,5,6-tricyclic ring system. The formation of three trithiahexaphyrins are also reported into which amino groups have been inserted, and which exhibit an azamethylene bridge between a pyrrolic nitrogen atoms and adjacent thiophene $\beta$ carbon atoms to form 5,7,5-tricyclic internal ring systems.

\section{Results and Discussion}

Synthesis and characterization: In an initial experiment, a solution of [28]trithiahexaphyrin (TTHP, 1) with a large excess of $\mathrm{CuCl}$ in DMF was heated under reflux for 48 hours and produced two major products after column chromatography. The less polar red compound (55\% yield) with $R_{\mathrm{f}}$ value of 0.19 in $\mathrm{CH}_{2} \mathrm{Cl}_{2}$ /hexane (1:1) has an absorption spectrum with $\lambda_{\max }$ of $519 \mathrm{~nm}(\log \varepsilon=4.95)$ in toluene; this is distinctly different from $\lambda_{\max }$ of 480 and $553 \mathrm{~nm}$ for the starting [28]trithiahexaphyrin. (Figure 1). The comparable extinction coefficient suggests that the ring structure and the conjugated system are retained. The FAB mass of 1352.88 indicates the elimination of a $\mathrm{HCl}$ unit to produce a fused-ring NFTTHP (2) as shown in Scheme 1.

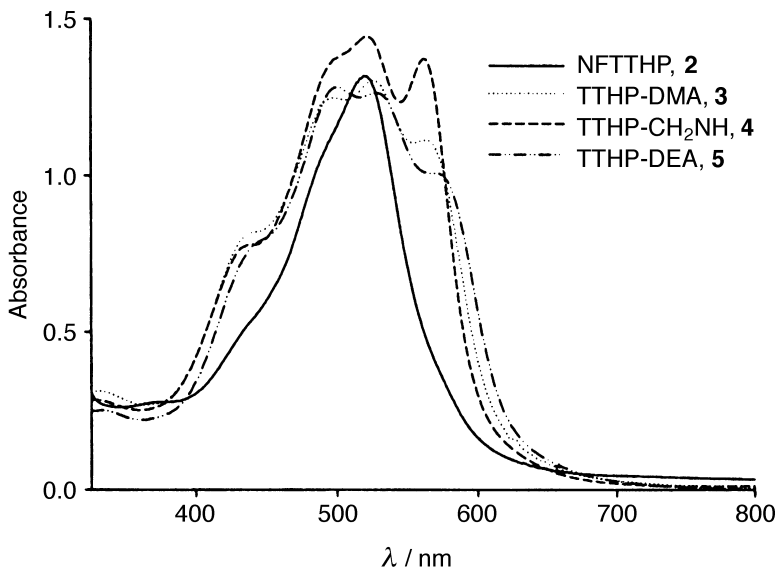

Figure 1. The absorption spectra of $\mathbf{2}, \mathbf{3}, \mathbf{4}$, and $\mathbf{5}$ in toluene.

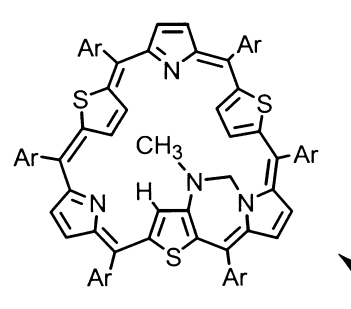

TTHP-DMA, 3

$\left[\mathrm{Cu}\left(\mathrm{CH}_{3} \mathrm{CN}\right)_{4}\right]^{+} \mathrm{BF}_{4}^{-}$ DMF, reflux

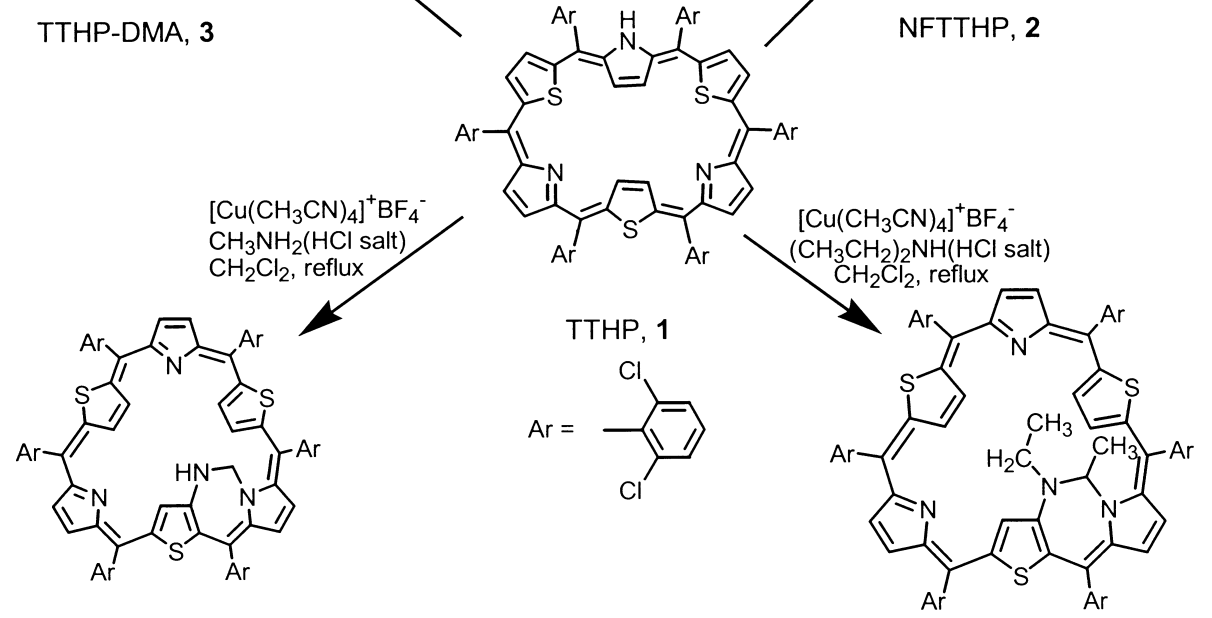

$\mathrm{CuCl}$

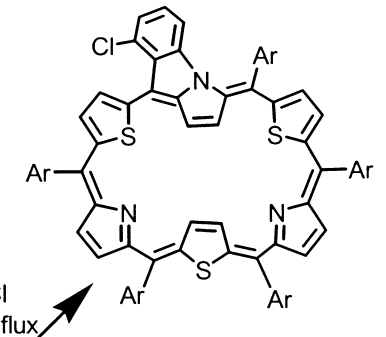

NFTTHP, 2

TTHP- $\mathrm{CH}_{2} \mathrm{NH}, 4$

TTHP-DEA, 5

Scheme 1. 
The polar purple compound (12\% yield) was eluted with $\mathrm{CH}_{2} \mathrm{Cl}_{2} / \mathrm{MeOH}$ (30:1) and has an electronic spectrum with $\lambda_{\max }$ at $526 \mathrm{~nm}(\log \varepsilon=3.82)$ and fine structures at 433, 498, and $563 \mathrm{~nm}$ in toluene. The FAB mass of 1429.1 indicates the insertion of a dimethyl amino group to form TTHP-DMA (3). The replacement of $\mathrm{CuCl}$ with $\left[\mathrm{Cu}\left(\mathrm{CH}_{3} \mathrm{CN}\right)_{4}\right] \mathrm{BF}_{4}$ increases the yield of 3 to $65 \%$ with only a trace amount of $\mathbf{2}$. In addition, carrying out the reaction in $\mathrm{CH}_{2} \mathrm{Cl}_{2}$ and in the presence of excess dimethylamine and $\left[\mathrm{Cu}\left(\mathrm{CH}_{3} \mathrm{CN}\right)_{4}\right]\left(\mathrm{BF}_{4}\right)$ yields $51 \%$ of $\mathbf{3}$ after refluxing for three hours. The successful reaction with dimethylamine as starting material suggests that the Lewis-acid-catalyzed decomposition of DMF is the most probable source of dimethylamino group for the formation of 3 when DMF is used as the solvent. ${ }^{[20]}$ The control experiment demonstrated that the reaction will not proceed in the absence of $\mathrm{Cu}^{\mathrm{I}}$. To broaden the scope of this ring-modification reaction, $\mathrm{CH}_{3} \mathrm{NH}_{2} \cdot \mathrm{HCl}$ was used as starting material; it reacts with 1 in the presence of $\left[\mathrm{Cu}\left(\mathrm{CH}_{3} \mathrm{CN}\right)_{4}\right]\left(\mathrm{BF}_{4}\right)$ to give TTHP$\mathrm{CH}_{2} \mathrm{NH}$ (4), which was isolated in $55 \%$ yield. The using of $(\mathrm{Et})_{2} \mathrm{NH} \cdot \mathrm{HCl}$ as base gives $57 \%$ yield of TTHP-DEA (5) (Scheme 1). The UV/Vis spectra of $\mathbf{4}$ and $\mathbf{5}$ resemble $\mathbf{3}$ and broad absorption bands from 400 to $600 \mathrm{~nm}$ with $\lambda_{\max }$ at around $520 \mathrm{~nm}$ and distinctive fine structures are observed.

NMR spectroscopy: The ${ }^{1} \mathrm{H}$ NMR spectra of fused-ring trithiahexaphyrin NFTTHP (2) are found to be critically temperature dependent. At room temperature, only those protons on the dichlorophenyl rings are distinguishable in ${ }^{1} \mathrm{H}$ NMR spectrum with broad, weak signals for the $\beta$-pyrrolic and thiophenic protons. As the temperature is lowered the spectrum resolves and assignment is possible. This observation suggests that the $\mathrm{N}$-fused trithiahexaphyrin is in a dynamic process at room temperature and demonstrates the flexibility of this expanded porphyrin. ${ }^{[21]}$ At low-temperature the rate of structure change is reduced relative to the NMR timescale. Figure 2 shows the HSQC NMR spectrum of 2 at $-40^{\circ} \mathrm{C}$ in $\left[\mathrm{D}_{8}\right] \mathrm{THF}$. Specifically, the peaks from $\delta=6.6$ to $7.8 \mathrm{ppm}$ are protons at meta- and para-positions in five dichlorophenyl rings. These peaks are observed at room temperature and suggest a higher rotation barrier; this is consistant with the high steric constraints of the ortho substituents on the dichlorophenyl rings, which inhibit free rotation. The peak at $\delta=11.14 \mathrm{ppm}$ is assigned to the water molecules trapped inside the trithiahexaphyrin ring, while that at $\delta=5.61 \mathrm{ppm}$ is assigned to the surrounding water molecules. The observation of no corresponding ${ }^{13} \mathrm{C}$ signals on HSQC and variable integration values correlating to the water contents of solvent agree with the assignment of $\delta=$ 11.14 and $5.61 \mathrm{ppm}$ as solvated water signals.

With the assistance of COSY and HSQC NMR spectra, the inner core $\beta$-thiophenic and $\beta$-pyrrolic protons of $\mathbf{2}$ are assigned as $\delta=12.34,12.30,11.06$, and $10.53 \mathrm{ppm}$. The eight doublets for the peripheral $\beta$-thiophenic and $\beta$-pyrrolic protons span in the range of $\delta=5.0$ to $6.2 \mathrm{ppm}$. Noticeably, the peaks at $\delta=5.03$ and 5.04 ppm overlapped and integrated into two protons. The pattern of chemical shifts of $\beta$-protons resembles the starting [28]trithiahexaphyrin with upfieldshifted peripheral protons and downfield-shifted inner core protons as a result of the paratropic shifts of the antiaromatic ring current. ${ }^{[22]}$ The doublet at $\delta=5.29$ ppm correlated with a triplet at $\delta=6.64 \mathrm{ppm}$ and has larger coupling constant $(14 \mathrm{~Hz})$ relative to the pyrrolic and thiophenic $\beta$-protons. The triplet at $\delta=6.64 \mathrm{ppm}$ further correlates to a peak at $\delta=$ $6.96 \mathrm{ppm}$. These three peaks are assigned as the protons on the benzene ring of the fused tricyclic unit according to their correlations in the COSY spectrum.

The NMR spectrum of $\mathbf{3}$ in $\left[\mathrm{D}_{8}\right]$ THF is temperature independent (Figure 3). Unlike starting trithiahexaphyrin and 2 , the NMR pattern of $\mathbf{3}$ suggests that the compound exhibits a triangular geometry. One singlet $(\delta=14.81 \mathrm{ppm})$ and four doublets $(\delta=15.96,15.85,15.19$, and $13.24 \mathrm{ppm})$ are located in the downfield region and corresponded to

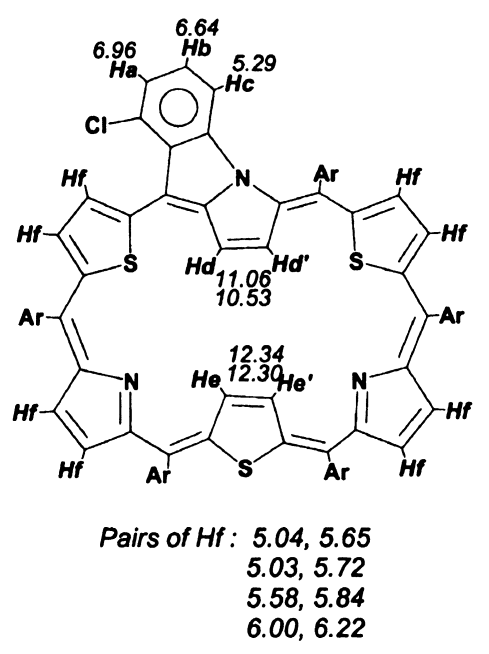

Figure 2. HSQC spectrum of 2 at $-40^{\circ}$ in $\left[\mathrm{D}_{8}\right] \mathrm{THF}$.

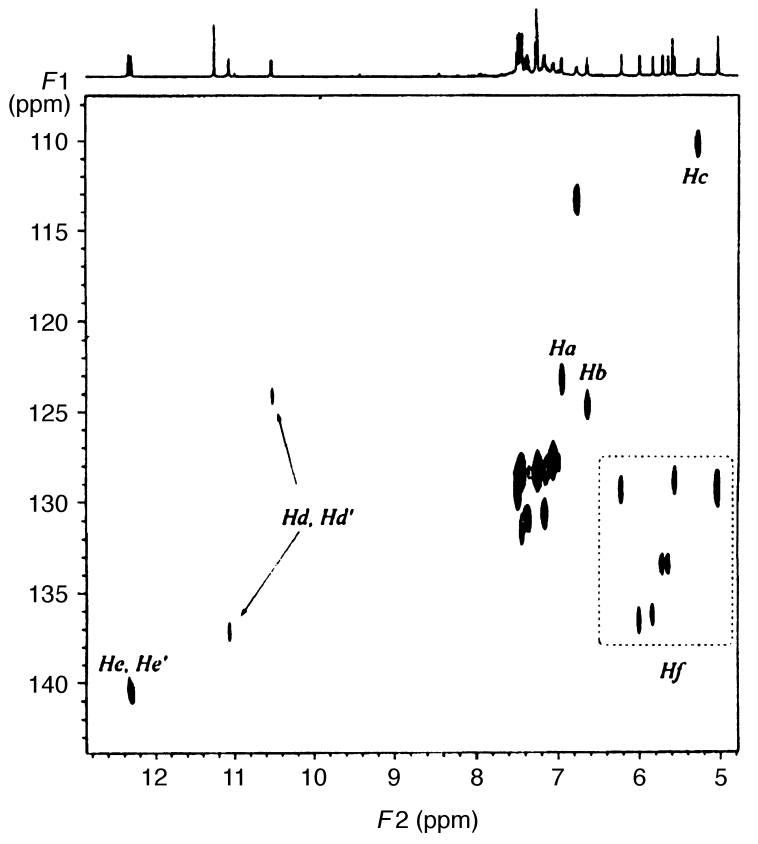




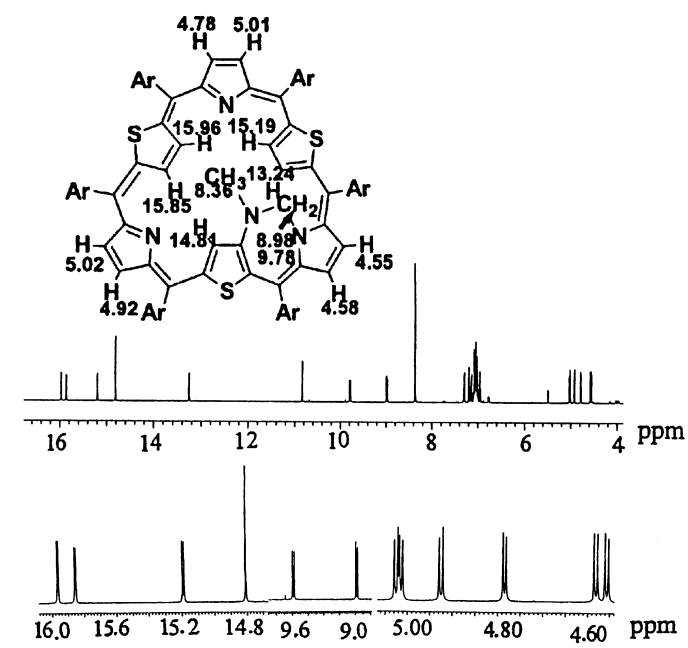

Figure 3. The ${ }^{1} \mathrm{H}$ NMR spectrum of $\mathbf{3}$ in $\left[\mathrm{D}_{8}\right] \mathrm{THF}$ at room temperature (top). Selected region of $\mathbf{3}$ (bottom). The chemical shifts for the protons on the fused hexaphyrin ring (inserted structure of $\mathbf{3}$ )

$\beta$-thiophenic protons inside the hexaphyrin core. The bonding of the nitrogen atom of the inserted azamethylene group to the thiophenic $\beta$-carbon atoms results in a singlet peak at $\delta=$ $14.81 \mathrm{ppm}$. The COSY and HSQC spectra suggests that the proton signal at $\delta=15.96 \mathrm{ppm}$ coupling with $\delta=15.85 \mathrm{ppm}$ are protons at the $\beta$-carbon atom on the same thiophene, while the signals at $\delta=15.19$ and $13.24 \mathrm{ppm}$ are paired up and can be assigned to protons on the thiophene group next to the azamethylene group. Assisted by COSY, HSQC, and homonuclear decoupling, six doublets within the range of $\delta=4.5$ and $5.2 \mathrm{ppm}$ are paired into three groups (4.58/4.55, 4.78/5.01, $4.92 / 5.02)$ and are assigned to the peripheral $\beta$-pyrrolic protons. The patterns of the NMR structure suggest the conservation of antiaromatic character dominated by paratropic ring current effect. Interestingly, the most deshielding peak at $\delta=16 \mathrm{ppm}$ for $\mathbf{3}$ is shifted about $4 \mathrm{ppm}$ downfield relative to that in $\mathbf{2}$, and suggests that either that ring fusing of 2 diminishes ring current or that the 5,5,6-tricyclic ring of $\mathbf{2}$ exhibits internal current and affects the antiaromatic character. The methyl group inside the trithiahexaphyrin ring is located as a singlet peak and integrated into three protons at $\delta=8.36 \mathrm{ppm}$. The HSQC spectrum shows that doublets at $\delta=8.98$ and $9.78 \mathrm{ppm}$, which have identical coupling constants of $12 \mathrm{~Hz}$, are correlated to the same carbon atom with a signal at $\delta=73.71 \mathrm{ppm}$ in the ${ }^{13} \mathrm{C}$ NMR spectrum and are assigned to two protons of the methylene group on the azamethylene unit.

The NMR spectra of $\mathbf{4}$ and $\mathbf{5}$ resemble $\mathbf{3}$. For the compound 4, with methylamine $\cdot$ hydrochloride as starting base, the singlet at $\delta=16.13$ and the doublets at $\delta=13.80,16.10$, 16.82 , and $16.67 \mathrm{ppm}$ are assigned as inner core $\beta$-pyrrolic protons (Figure 4). Two doublets at $\delta=9.06$ and 14.16 and a quartet at $\delta=10.37 \mathrm{ppm}$ give cross peaks with each other on COSY and are assigned as the protons on inserted azamethylene subunit. Among those three peaks, $\delta=9.06$ and $10.37 \mathrm{ppm}$ correlate to the same carbon on HSQC, while the relatively broad doublet at $\delta=14.16 \mathrm{ppm}$ has no correlated ${ }^{13} \mathrm{C}$ signal in the HSQC spectrum and is assigned as the $\mathrm{NH}$ proton. The ${ }^{1} \mathrm{H}$ NMR signals for six peripheral $\beta$-pyrrolic

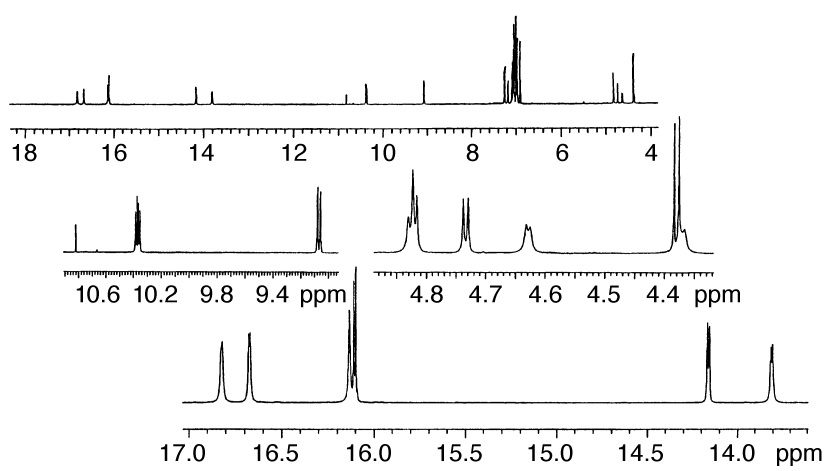

Figure 4. The ${ }^{1} \mathrm{H}$ NMR spectrum of 4 in $\left[\mathrm{D}_{8}\right] \mathrm{THF}$ at room temperature (top). Selected region of the ${ }^{1} \mathrm{H}$ NMR spectrum of $\mathbf{4}$ (middle and bottom).

protons are located in between $\delta=4.37$ and $4.83 \mathrm{ppm}$. The peaks are broadened and overlapped significantly. Nevertheless, the overall patterns for these six protons are similar to 3. For ${ }^{1} \mathrm{H}$ NMR spectrum of compound 5 (Figure 5), a triplet

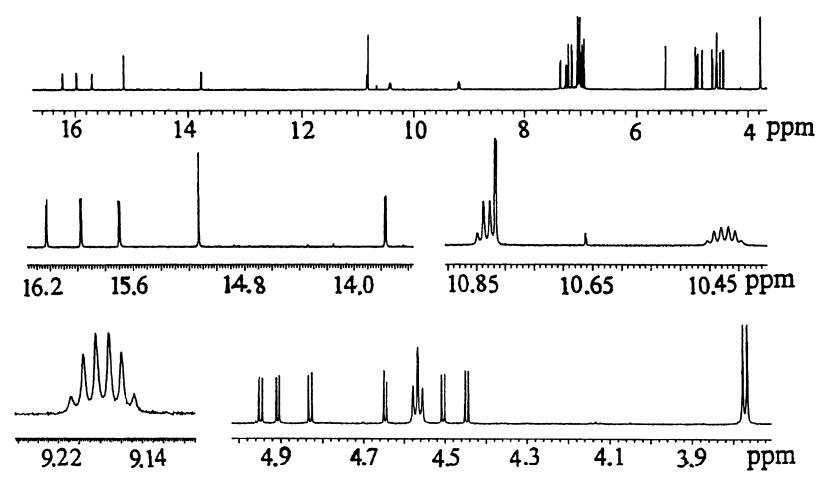

Figure 5. The ${ }^{1} \mathrm{H}$ NMR spectrum of $\mathbf{5}$ in $\left[\mathrm{D}_{8}\right] \mathrm{THF}$ at room temperature (top). Selected region of $\mathbf{5}$ (middle and bottom).

and a doublet both integrated into three protons are located at $\delta=4.56$ and $3.76 \mathrm{ppm}$ and are assigned to the methyl group connected to methylene and methyne, respectively. The proton signal for the methyne splits into a quartet and is located at $\delta=10.83 \mathrm{ppm}$. The two protons on methylene group that are not magnetically equivalent are located at $\delta=$ 9.18 and $10.43 \mathrm{ppm}$ according to the COSY spectrum. These two peaks couple with the neighboring methyl group and then further couple with the proton on methyne to give six line patterns. The peak at $\delta=10.82 \mathrm{ppm}$ is assigned as the water molecule trapped inside the trithiahexaphyrin cavity. One singlet and four doublets for inner core $\beta$-thiophenic protons are located in downfield region $(\delta=13.8-16.2 \mathrm{ppm})$, while six doublets for peripheral $\beta$-pyrrolic protons are located around $\delta=4 \mathrm{ppm}$. This pattern agrees with a triangular trithiahexaphyrin contour with antiaromatic character.

X-ray structures of 2 and 3: The structures of the N-fused trithiahexaphyrin 2 and the azamethylene-inserted trithiahexaphyrin $\mathbf{3}$ were confirmed by single-crystal X-ray analysis. Crystals of $\mathbf{3}$ were obtained from a slow diffusion of hexane into a mixed solution of $\mathbf{3}$ in methylene chloride and THF, and the structure of free-base form of $\mathbf{3}$ was obtained. The free-base NFTTHP does not crystallize well and the bishy- 
droperchlorate salt of $\mathbf{2}$ was obtained from the diffusion of hexane into a solution of $\mathbf{2}$ in methylene chloride acidified with perchloric acid. Importantly, the structure of bishydroperchlorate salt of $\mathbf{2}$ reveals the hydrogen bonding and anion interactions in the fused-ring expanded porphyrins.

The bishydroperchlorate salt of 2 (Figure 6) shows a rectangular shape of the trithiahexaphyrin ring with alternative pyrrole and thiophene units linked through meso-carbon
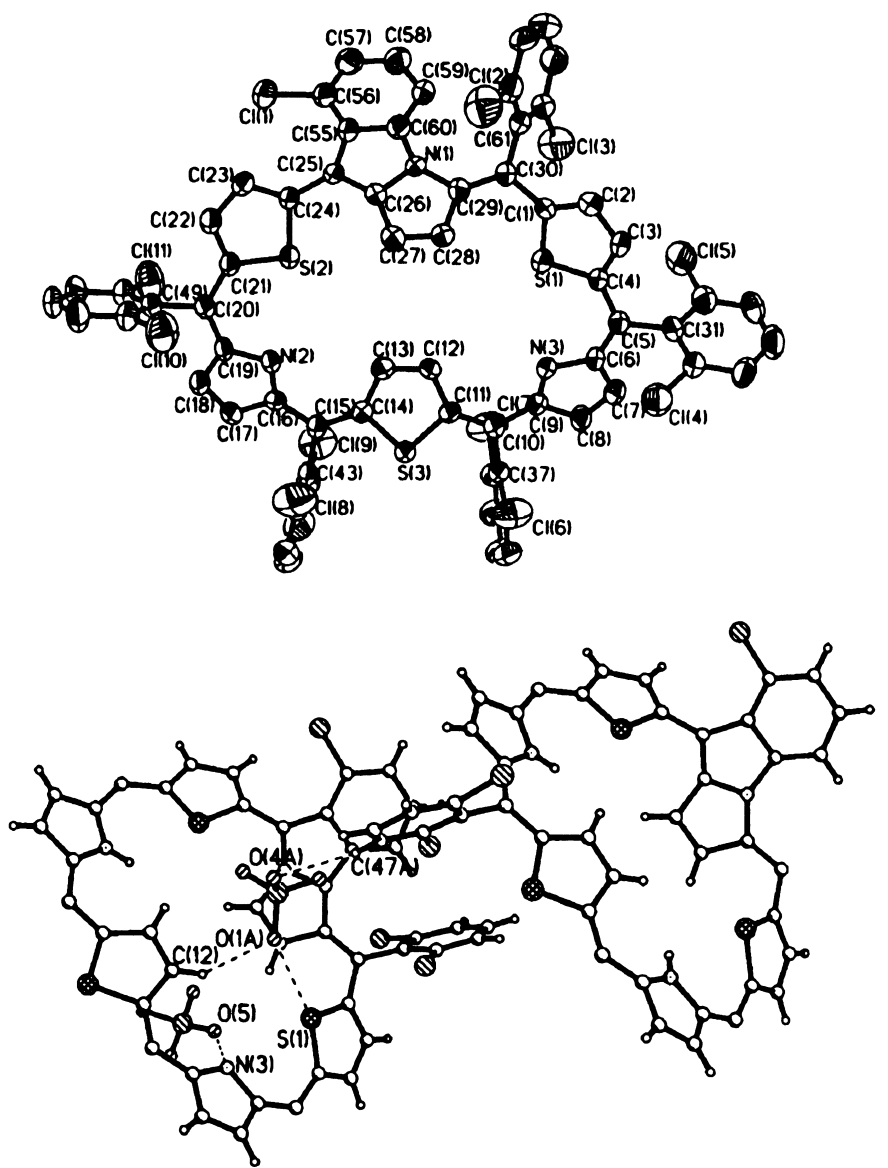

Figure 6. Crystal structure of perchlorate salt of $\mathbf{2}$ (top; perchlorate ions are omitted) and closed-contact interactions of perchlorate salts and $\mathbf{2}$ (bottom; unrelated phenyl rings are omitted for clarity).

atoms. One of the chlorides on the dichlorophenyl ring is eliminated and joints directly to the deprotonated pyrrolic nitrogen to form a 5,5,6-tricyclic ring system. The relatively long distances of $1.410(6) \AA$ for the pyrrolic nitrogen to the carbon atom on the benzene ring, $\mathrm{N}(1)-\mathrm{C}(60)$, and 1.458(6) $\AA$ for meso-carbon to that on the benzene ring, $\mathrm{C}(25)-\mathrm{C}(55)$, suggest that there is only limited electron delocalization in the tricyclic system. The bishydroperchlorate salt of $\mathbf{2}$ exhibits a non-planar bowl-shaped trithiahexaphyrin ring with a mean deviation of $0.332 \AA$ from the plane defined by the 36 core atoms on the hexaphyrin ring. The tricyclic ring cants significantly with a tilting angle of $50^{\circ}$ from the mean plane. According to the packing diagram (Figure 6), one of the perchlorate ions sits below the fused hexaphyrin ring and hydrogen bonds to a pyrrolic nitrogen with a distance of $2.851 \AA$ for $\mathrm{O}(5) \cdots \mathrm{N}(3)$, while the other perchlorate ion sits above the ring with close contacts to a thiophenic sulphur atom, a thiophenic $\beta$-hydrogen atom $(\mathrm{H}(12)$ on $\mathrm{C}(12))$, and a hydrogen on the phenyl ring atom $(\mathrm{H}(47 \mathrm{~A})$ on $\mathrm{C}(47 \mathrm{~A}))$ of the neighbouring trithiahexaphyrin. The distance of the $\mathrm{O}(1 \mathrm{~A})$ to the sulphur $\mathrm{S}(1)$ is $3.212 \AA$, while the distances of $\mathrm{O}(1 \mathrm{~A})$ $\mathrm{H}(12)$ and $\mathrm{O}(4 \mathrm{~A})-\mathrm{H}(47 \mathrm{~A})$ are 2.549 and $2.520 \AA$, respectively.

Interestingly, the $\mathrm{X}$-ray analysis of compound $\mathbf{3}$ indicates a triangular contour of the hexaphyrin ring (Figure 7); this is in agreement with the NMR assignments. The thiophenic $\beta$ carbon $(\mathrm{C}(2))$ is joined to the nitrogen $(\mathrm{N}(4))$ on the
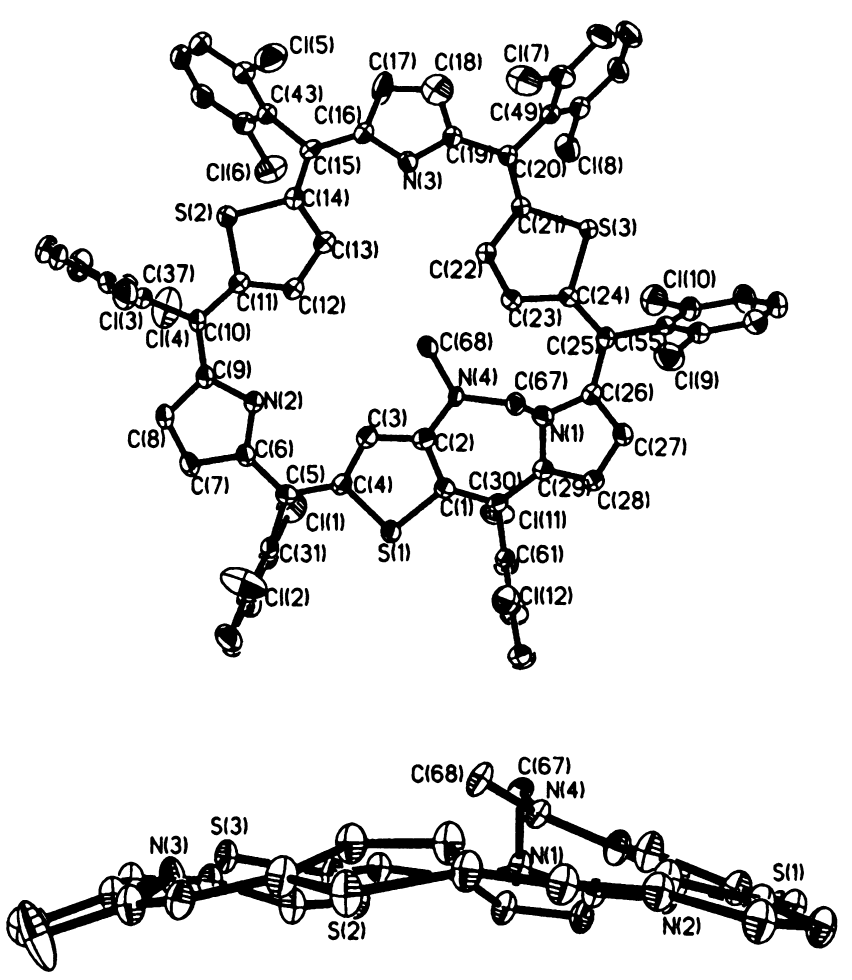

Figure 7. Front view (top) and side view of $\mathbf{3}$ (bottom; phenyl rings are omitted in the side view for clarity).

azamethylene unit, while the nitrogen atom (N(1)) of the neighboring pyrrole ring is joined to the methylene carbon $(\mathrm{C}(67))$ to form a 5,7,5-tricyclic ring. The azamethylene group is disordered over two positions with $50 \%$ occupancy on each site. The bond distances of 1.436(9) and 1.519(9) $\AA$ for $\mathrm{N}(4)-\mathrm{C}(67)$ and $\mathrm{C}(67)-\mathrm{N}(1)$, respectively, are all in the single bond range and suggest that the ring fusion does not alter the conjugation system of the hexaphyrin ring. The bowl-shaped hexaphyrin ring has a relatively small $(0.276 \AA)$ mean deviation of atoms from the plane defined by 36 hexaphyrin core atoms. The three atoms on the azamethylene unit deviate significantly from the mean plane with an average deviation of $1.449 \AA$. The deviation of the azamethylene from the mean plane creates different chemical environments for the two protons on the relatively rigid methylene carbon. One of the hydrogen atoms on the methylene carbon of the azamethylene group is located closer to the central of trithiahexaphyrin ring, while the other is directed outward; this explains the different chemical shifts for these two protons in the ${ }^{1} \mathrm{H}$ NMR spectra of in $\mathbf{3}$ as well as in $\mathbf{4}$ and $\mathbf{5}$. 


\section{Conclusion}

For the formation of $\mathbf{2}$, it is expected that the interaction of $\mathrm{Cu}^{\mathrm{I}}$ and chloride on the dichlorophenyl group enhances the charge separation in the $\mathrm{C}-\mathrm{Cl}$ bond involved and facilitate the nucleophilic attack of pyrrolic nitrogen on the the phenyl ring. The elimination of $\mathrm{HCl}$ completes the ring closure to form the $\mathrm{N}$-fused product. The mechanisms for the formations of azamethylene inserted compounds, however, are not completely understood. The reaction requires activation of the $\mathrm{C}-\mathrm{H}$ bonds at a $\beta$-thiophenic carbon atom and a methyl group. The fact that the presence of $\mathrm{Cu}^{\mathrm{I}}$ appears to essential suggests that $\mathrm{Cu}^{\mathrm{I}}$ is involved in the $\mathrm{C}-\mathrm{H}$ bond-activation processes. ${ }^{[23]}$ A detailed study with different copper(I) complexes and amines to explore the mechanism of the insertion reaction in this type of ring-modification reaction is underway. Noticeably, the amino-substituted thiophene or porphyrin is relatively unexplored $;^{[24]}$ this report suggests a method for the formation of a $\mathrm{C}-\mathrm{N}$ bond at a $\beta$-thiophenic position.

To our knowledge, the formation of internal 5,7,5- or 5,5,6tricyclic rings described herein is the first report of a metalion-mediated ring-fusion reaction of expanded porphyrins. Most antibiotics or antifungi contain heterocyclic rings, for example, the natural product of mitomycin $c$ exhibits a 5,5,6tricyclic ring system and is a strong antibiotic. ${ }^{[25]}$ Although further reactions are required to modify the internal heterocyclic ring to introduce, for example, a functionalized antibiotic unit into the expanded porphyrin, this report provides a convenient route that can introduce multiple functionalities to a photoactive expanded porphyrin or porphyrin analogue.

\section{Experimental Section}

General information: Solvents were distilled under nitrogen from appropriate drying agents ${ }^{[26]}$ and stored in dried, $\mathrm{N}_{2}$-filled flasks over $4 \AA$ molecular sieves. Pyrrole was freshly distilled from calcium hydride before use. Otherwise all starting materials were obtained commercially and used without further purification. Column chromatography was performed over silica (Merck, 230-400 mesh). UV/Vis spectra were recorded on a Hewlett-Packard 8453 spectrophotometer. Analyses of carbon, hydrogen, and nitrogen were obtained with a $\mathrm{CHN}$ analyzer (Heraeus). NMR spectra were obtained on a Varian Unity Inova-600 spectrometer. Mass spectra were recorded on a Finnigan/Thermo Quest MAT 95XL or a JEOL JMS SX/SX 102A mass spectrometer.

Preparation of [28] $\mathbf{N}_{3} \mathbf{S}_{3}$-hexaphyrin (1): A vessel $(50 \mathrm{~mL})$ is charged with $\mathrm{Cl}_{2}$ diol $(210 \mathrm{mg}, 0.486 \mathrm{mmol})$ and pyrrole $(34 \mu \mathrm{L}, 0.524 \mathrm{mmol})$ in $\mathrm{CH}_{2} \mathrm{Cl}_{2}$ $(25 \mathrm{~mL})$ and nitrogen was bubbled through the mixture for 15 mins. $\mathrm{BF}_{3}$. $\mathrm{OEt}_{2}(30 \mu \mathrm{L}, 7.55 \mathrm{~mm})$ was added, and the solution was stirred at room temperature for $1.5 \mathrm{~h}$. DDQ $(0.15 \mathrm{~g}, 0.661 \mathrm{mmol})$ was then added, and the mixture was stirred continuously for $30 \mathrm{~min}$. The solvent was removed on a rotary evaporator, and the residue redissolved in a minimum amount of $\mathrm{CH}_{2} \mathrm{Cl}_{2}$. The solution of the crude product was loaded to the top of a silica column $(5 \times 20 \mathrm{~cm})$ packed with $\mathrm{CH}_{2} \mathrm{Cl}_{2} /$ hexane $(1: 1)$ and eluted with $\mathrm{CH}_{2} \mathrm{Cl}_{2} /$ hexane (1:1). A yellow solution $\left(R_{f}=0.50\right.$ in $1: 1 \mathrm{CH}_{2} \mathrm{Cl}_{2} /$ hexane $)$ was eluted first and had a UV/Vis spectrum identical to dithiaporphyrin. The solution of dithiaporphyrin was collected and concentrated to dryness to have $\mathrm{S}_{2}$ TDCPP (41.4 mg, $20 \%$ yields). The desired [28] $\mathrm{N}_{3} \mathrm{~S}_{3}$-hexaphyrin eluted out as a red solution $\left(R_{\mathrm{f}}=0.21\right.$ in $1: 1 \mathrm{CH}_{2} \mathrm{Cl}_{2} /$ hexane $)$ and was collected and concentrated to dryness on a rotary evaporator. The solid of [28] $\mathrm{N}_{3} \mathrm{~S}_{3}$-hexaphyrin was then dissolved in minimum amount of $\mathrm{CH}_{2} \mathrm{Cl}_{2}$ and recrystallized by a slow addition of hexane $(33.7 \mathrm{mg}, 15 \%)$. UV/Vis $\left(\mathrm{CH}_{2} \mathrm{Cl}_{2}\right): \lambda_{\max }(\log \varepsilon)=480(5.10), 553 \mathrm{~nm}$ (4.92); elemental analysis calcd (\%) for $\mathrm{C}_{66} \mathrm{H}_{31} \mathrm{~N}_{3} \mathrm{~S}_{3} \mathrm{Cl}_{12} \cdot 0.5 \mathrm{CH}_{2} \mathrm{Cl}_{2} \cdot 0.25$ hexane: C 56.26, H 2.46, N 2.89; found: C 56.66, H 2.88, N 2.43; FAB-MS: $m / z$ : $1388.86\left[M^{+}+\mathrm{H}\right]$; HRMS: $m / z: 1388.8016\left[M^{+}+\mathrm{H}\right] ;{ }^{1} \mathrm{H}$ NMR $\left(600 \mathrm{MHz}, \mathrm{CD}_{2} \mathrm{Cl}_{2}, 25^{\circ} \mathrm{C}\right): \delta=4.08(\mathrm{br}$, $1 \mathrm{H}), 4.20\left(\mathrm{~d},{ }^{3} J(\mathrm{H}, \mathrm{H})=6 \mathrm{~Hz}, 2 \mathrm{H}\right), 4.31\left(\mathrm{~d},{ }^{3} J(\mathrm{H}, \mathrm{H})=6 \mathrm{~Hz}, 2 \mathrm{H}\right), 4.41(\mathrm{~d}$, $\left.{ }^{3} J(\mathrm{H}, \mathrm{H})=4.8 \mathrm{~Hz}, 2 \mathrm{H}\right), 4.67\left(\mathrm{~d},{ }^{3} J(\mathrm{H}, \mathrm{H})=5.4 \mathrm{~Hz}, 2 \mathrm{H}\right), 6.87-7.15(\mathrm{~m}, 18 \mathrm{H})$, $14.27(\mathrm{~s}, 2 \mathrm{H}), 19.20(\mathrm{~s}, 2 \mathrm{H}) ;{ }^{13} \mathrm{C} \mathrm{NMR}\left(\mathrm{CD}_{2} \mathrm{Cl}_{2}\right): \delta=119.52,123.27,123.52$, 127.54 (2), 127.65, 128.24 (2), 128.34 (2), 129.84, 130.04, 130.24, 131.85, 132.97, 134.12, 134.96, 135.13, 135.20, 135.31, 135.48, 135.86, 136.09, 137.05, $140.40,149.54,150.34,157.00,159.54,174.06$.

Preparation of NFTTHP (2) and TTHP-DMA (3): A round-bottomed flask containing $1(0.042 \mathrm{~g}, 0.029 \mathrm{mmol})$ and $\mathrm{CuCl}(0.059 \mathrm{~g}, 0.606 \mathrm{mmol})$ in DMF $(50 \mathrm{~mL})$ was heated to reflux in an inert atmosphere dry box. The reaction was monitored by frequently checking UV/Vis spectra of the aliquots. The reaction was completed after $48 \mathrm{~h}$, and the solvent was removed by a rotavapor. The resulting crude solid was dissolved in minimum amount of $\mathrm{CH}_{2} \mathrm{Cl}_{2}$, loaded on the top of a column filled with slurry silica gel in $\mathrm{CH}_{2} \mathrm{Cl}_{2}$ /hexane (1:1) and eluted with the same solvent. The fraction of red solution was collected. The solvent was removed by rotary evaporator and recrystallized from $\mathrm{CH}_{2} \mathrm{Cl}_{2}$ /hexane to give $\mathbf{2}$. $(0.028 \mathrm{~g}, 55.4 \%)$ The eluting solvent of the column was then changed to $\mathrm{CH}_{2} \mathrm{Cl}_{2} / \mathrm{MeOH}(30: 1)$ and more polar compound 3 was collected as a red solution. After the solvent removal and recrystallization from $\mathrm{CH}_{2} \mathrm{Cl}_{2}$ / hexane, 3 (5 mg, 12.4\% yield) was obtained as red crystalline solid.

Alternatively, 3 can be obtained with higher yield by replacing $\mathrm{CuCl}$ with $\left[\mathrm{Cu}\left(\mathrm{CH}_{3} \mathrm{CN}\right)_{4}\right]\left(\mathrm{BF}_{4}\right) \cdot\left[\mathrm{Cu}\left(\mathrm{CH}_{3} \mathrm{CN}\right)_{4}\right]\left(\mathrm{BF}_{4}\right)$ was fresh prepared by using the literature method. ${ }^{[27]} \mathrm{In}$ an inert-atmosphere glove box, $\mathrm{CuCl}(0.06 \mathrm{~g}$, $0.61 \mathrm{mmol})$ and $\mathrm{AgBF}_{4}(0.12 \mathrm{~g}, 0.62 \mathrm{mmol})$ in $\mathrm{CH}_{3} \mathrm{CN}(20 \mathrm{~mL})$ were stirred $24 \mathrm{~h}$ at room temperature. The $\mathrm{AgCl}$ precipitate was filtered and the solution of $\mathrm{Cu}^{\mathrm{I}}$ in acetonitrile was transfered to another round bottom flask $(100 \mathrm{~mL})$ containing $\mathbf{1}(0.04 \mathrm{~g}, 0.03 \mathrm{mmol})$ in DMF $(20 \mathrm{~mL})$. The mixture of solvent was heated to reflux under nitrogen and frequently monitored by $\mathrm{UV} / \mathrm{Vis}$ spectroscopy. After $48 \mathrm{~h}$, the solvent was removed under vacuum and separated by silica-gel column chromatography. Elution with $\mathrm{CH}_{2} \mathrm{Cl}_{2}$ / $\mathrm{CH}_{3} \mathrm{CN}$ (30:1) gave desired red solution of $\mathbf{3}$. The solution was dried and recrystallized from $\mathrm{CH}_{2} \mathrm{Cl}_{2} /$ hexane to give $0.027 \mathrm{~g}(65 \%)$ of $\mathbf{3}$.

Compound 2: UV/vis (toluene): $\lambda_{\max }(\log \varepsilon)=519 \mathrm{~nm}(4.95) ;{ }^{1} \mathrm{H}$ NMR $\left(\left[\mathrm{D}_{8}\right] \mathrm{THF}, 600 \mathrm{MHz},-40^{\circ} \mathrm{C}\right): \delta=5.03(\mathrm{~d}, 1 \mathrm{H}), 5.04(\mathrm{~d}, 1 \mathrm{H}), 5.29(\mathrm{~d}, 1 \mathrm{H})$, $5.58(\mathrm{~d}, 1 \mathrm{H}), 5.65(\mathrm{~d}, 1 \mathrm{H}), 5.72(\mathrm{~d}, 1 \mathrm{H}), 5.84(\mathrm{~d}, 1 \mathrm{H}), 6.00(\mathrm{~d}, 1 \mathrm{H}), 6.22(\mathrm{~d}$, $1 \mathrm{H}), 6.64(\mathrm{t}, 1 \mathrm{H}), 6.77(\mathrm{~m}, 1 \mathrm{H}), 6.96(\mathrm{~d}, 1 \mathrm{H}), 7.05-7.50(\mathrm{~m}, 14 \mathrm{H}), 10.53(\mathrm{~d}$, $1 \mathrm{H}), 11.06(\mathrm{~d}, 1 \mathrm{H}), 12.30(\mathrm{~d}, 1 \mathrm{H}), 12.34(\mathrm{~d}, 1 \mathrm{H})$; FAB-MS: $m / z: 1352.88$ $\left[M^{+}+\mathrm{H}\right]$; HRMS : $m / z$ : $1352.8846\left[M^{+}+\mathrm{H}\right]$.

Transfer of the same amount $\mathrm{Cu}^{\mathrm{I}}$ solution $(0.03 \mathrm{M}, 20 \mathrm{~mL})$ mentioned above, to a round-bottomed flask $(100 \mathrm{~mL})$ containing $1(0.032 \mathrm{~g}$, $0.022 \mathrm{mmol})$ in anhydrous $\mathrm{CH}_{2} \mathrm{Cl}_{2}(50 \mathrm{~mL})$, followed by treatment with $\left(\mathrm{CH}_{3}\right)_{2} \mathrm{NH}$ (4 mL; $2.0 \mathrm{M}$ in THF) gave the starting solution without DMF. The solution was heated to reflux under nitrogen for $3 \mathrm{~h}$, and solvent was removed under vacuum. The crude material was purified over a silica-gel column loaded with $\mathrm{CH}_{2} \mathrm{Cl}_{2}$ and eluted with $\mathrm{CH}_{2} \mathrm{Cl}_{2} / \mathrm{CH}_{3} \mathrm{CN}$ (30:1). The red solution of $\mathbf{3}$ was collected, dried, and recrystallized from $\mathrm{CH}_{2} \mathrm{Cl}_{2} /$ hexane to have $0.017 \mathrm{~g}(51 \%)$ of $\mathbf{3}$.

Compound 3: UV/vis (toluene): $\lambda_{\max }(\log \varepsilon)=433(\mathrm{sh}), 498$ (3.81), 526 (3.82), $563 \mathrm{~nm}(3.76) ;{ }^{1} \mathrm{H}$ NMR $\left(600 \mathrm{MHz},\left[\mathrm{D}_{8}\right] \mathrm{THF}, 25^{\circ} \mathrm{C}\right): \delta=4.55(\mathrm{~d}$, $1 \mathrm{H}), 4.58(\mathrm{~d}, 1 \mathrm{H}), 4.79(\mathrm{~d}, 1 \mathrm{H}), 4.92(\mathrm{~d}, 1 \mathrm{H}), 5.01(\mathrm{~d}, 1 \mathrm{H}), 5.02(\mathrm{~d}, 1 \mathrm{H})$, $6.80-7.60(\mathrm{~m}, 18 \mathrm{H}), 8.36(\mathrm{~s}, 3 \mathrm{H}), 8.98(\mathrm{~d}, 1 \mathrm{H}), 9.78(\mathrm{~d}, 1 \mathrm{H}), 13.24(\mathrm{~d}, 1 \mathrm{H})$, $14.81(\mathrm{~s}, 1 \mathrm{H}), 15.19(\mathrm{~d}, 1 \mathrm{H}), 15.85(\mathrm{~d}, 1 \mathrm{H}), 15.96(\mathrm{~d}, 1 \mathrm{H})$; FAB-MS: $m / z$ : $1429.1\left[M^{+}+\mathrm{H}\right]$; HRMS: $m / z: 1429.8331\left[M^{+}+\mathrm{H}\right]$.

Preparation of TTHP-CH 2 NH (4): A round-bottomed flask was charged with [28]trithiahexaphyrin (40 mg, $0.029 \mathrm{mmol})$ and $\mathrm{CH}_{3} \mathrm{NH}_{2} \cdot \mathrm{HCl}$ (300 mg, $4.45 \mathrm{mmol}$ ) in anhydrous $\mathrm{CH}_{2} \mathrm{Cl}_{2}(50 \mathrm{~mL})$ and the mixture stirred at room temperature. The freshly prepared solution of $\left[\mathrm{Cu}\left(\mathrm{CH}_{3} \mathrm{CN}\right)_{4}\right] \mathrm{BF}_{4}$ $(0.03 \mathrm{M}, 20 \mathrm{~mL})$ was transfered into the flask, and the mixture was heated to reflux. The completeness of the reaction was monitored by taking aliquots from the solution and examining them by TLC. Additional portions of $\left[\mathrm{Cu}\left(\mathrm{CH}_{3} \mathrm{CN}\right)_{4}\right] \mathrm{BF}_{4}(0.03 \mathrm{M}, 10 \mathrm{~mL})$ were added into the reaction flask if the starting trithiahexaphyrin was detected after $2 \mathrm{~h}$. The reaction was halted and cooled to room temperature when no starting hexaphyrin was detected. After the solvent removal, the remaining red solid was dissolved in minimum amount of $\mathrm{CH}_{2} \mathrm{Cl}_{2} / \mathrm{CH}_{3} \mathrm{CN}(30: 1)$ and loaded onto the top of a silica column packed with the same solvent system. The red compound with $R_{\mathrm{f}}$ value of 0.2 on TLC under the same solvent system was collected and recrystallization from $\mathrm{CH}_{2} \mathrm{Cl}_{2} /$ hexane to afford $22 \mathrm{mg}$ of red compound of 4 
(yield: $54 \%$ ). UV/vis (toluene): $\lambda_{\max }(\log \varepsilon)=439(4.90), 496$ (sh, 5.14), $520 \mathrm{~nm}(5.17) ;{ }^{1} \mathrm{H}$ NMR $\left(600 \mathrm{MHz},\left[\mathrm{D}_{8}\right] \mathrm{THF}, 25^{\circ} \mathrm{C}\right): \delta=4.37(\mathrm{br}, 1 \mathrm{H}), 4.38$ $(\mathrm{d}, 1 \mathrm{H}), 4.63(\mathrm{br}, 1 \mathrm{H}), 4.73(\mathrm{~d}, 1 \mathrm{H}), 4.82(\mathrm{br}, 2 \mathrm{H}), 6.9-7.3(\mathrm{~m}, 18 \mathrm{H}), 9.06$ $(\mathrm{q}, 1 \mathrm{H}), 10.37(\mathrm{q}, 1 \mathrm{H}), 13.80(\mathrm{~d}, 1 \mathrm{H}), 14.16(\mathrm{~d}, 1 \mathrm{H}), 16.10(\mathrm{~d}, 1 \mathrm{H}), 16.13(\mathrm{~s}$, $1 \mathrm{H}), 16.67(\mathrm{~d}, 1 \mathrm{H}), 16.82(\mathrm{~d}, \mathrm{br}, 1 \mathrm{H}) ; \mathrm{FAB}-\mathrm{MS}: \mathrm{m} / \mathrm{z}: 1415.8\left[\mathrm{M}^{+}+\mathrm{H}\right]$; HRMS: $m / z: 1415.7816\left[M^{+}+\mathrm{H}\right]$.

Preparation of TTHP-DEA (5): The reaction procedures for 4 were applied to the preparation of 5 by using $\left(\mathrm{CH}_{3} \mathrm{CH}_{2}\right)_{2} \mathrm{NH} \cdot \mathrm{HCl}(300 \mathrm{mg}$, $2.74 \mathrm{mmol}$ ) as starting material. The polarity of $\mathbf{5}$ is close to $\mathbf{4}$ and the separation was carried out by a column packed with silica gel and eluted with $\mathrm{CH}_{2} \mathrm{Cl}_{2} / \mathrm{CH}_{3} \mathrm{CN}$ (30:1). After the removal of minor impurities, the dark red major product was collected. Solvent removal and recrystallization gave $24 \mathrm{mg}$ red solid of 5 (yield: $57 \%$ ). UV/Vis (toluene): $\lambda_{\max }$ (log $\varepsilon)=333$ (3.92), 441 (sh, 4.41), 500 (4.63), 528 (4.62), $574 \mathrm{~nm} \mathrm{(sh,} \mathrm{4.52);}$ ${ }^{1} \mathrm{H}$ NMR $\left(600 \mathrm{MHz},\left[\mathrm{D}_{8}\right] \mathrm{THF}, 25^{\circ} \mathrm{C}\right): \delta=3.76(\mathrm{~d}, 3 \mathrm{H}), 4.45(\mathrm{~d}, 1 \mathrm{H}), 4.51$ $(\mathrm{d}, 1 \mathrm{H}), 4.56(\mathrm{t}, 3 \mathrm{H}), 4.65(\mathrm{~d}, 1 \mathrm{H}), 4.83(\mathrm{~d}, 1 \mathrm{H}), 4.91(\mathrm{~d}, 1 \mathrm{H}), 4.95(\mathrm{~d}, 1 \mathrm{H})$, 6.9-7.3 (m, 18 H), 9.18 (sextet, $1 \mathrm{H}), 10.43$ (sextet, $1 \mathrm{H}), 10.83(\mathrm{q}, 1 \mathrm{H}), 13.77$ $(\mathrm{d}, 1 \mathrm{H}), 15.13(\mathrm{~s}, 1 \mathrm{H}), 15.70(\mathrm{~d}, 1 \mathrm{H}), 15.97(\mathrm{~d}, 1 \mathrm{H}), 16.23(\mathrm{~d}, 1 \mathrm{H})$; FABMS: $m / z: 1457.87\left[M^{+}+\mathrm{H}\right]$; HRMS: $m / z: 1457.8718\left[M^{+}+\mathrm{H}\right]$.

Crystal structure analyses: The X-ray diffraction data were collected on a Bruker SMART 1000 diffractometer equipped with a CCD detector. The structure was solved by the direct methods on $F^{2}$ and refined by the leastsquare method on $F^{2}$ by using the SHELXTL program. ${ }^{[28]}$ A SADABS absorption correction was made. ${ }^{[29]}$ CCDC-168792 and CCDC-168793 contain the supplementary crystallographic data for the paper. These data can be obtained free of charge via www.ccdc.cam.ac.uk/conts/retrieving.html (or from the Cambridge Crystallographic Data Center, 12 Union Road, Cambridge CB2 1EZ, UK; fax: $(+44) 1223-336-033$; or e-mail: deposit@ccdc.cam.ac.uk)

Data for $2 \mathbf{H}_{2}{ }^{2+} \cdot \mathbf{2} \mathbf{C l O}_{4}{ }^{-}: \mathrm{C}_{67} \mathrm{H}_{36} \mathrm{Cl}_{15} \mathrm{~N}_{3} \mathrm{O}_{9} \mathrm{~S}_{3}, M_{r}=1654.92$; crystals obtained from $\mathrm{CH}_{2} \mathrm{Cl}_{2}$ /hexane; crystal size $0.31 \times 0.08 \times 0.06 \mathrm{~mm}^{3 ;}$ triclinic, space group $P \overline{1}, a=13.3809(8), b=14.4347(9), c=18.8210(12) \AA, \alpha=93.925(2)^{\circ}$, $\beta=97.8800(10)^{\circ}, \quad \gamma=99.6130(10)^{\circ}, \quad V=3534.8(4) \AA^{3,} \quad Z=2, \quad \rho_{\text {calcd }}=$ $1.555 \mathrm{mg} \mathrm{m}^{-3} ; \mu=0.730 \mathrm{~mm}^{-1}, F(000)=1668 ; 22801$ measured reflections collected; 15753 observed reflections. $\left(F_{\mathrm{o}}^{2}>2 \rho F_{\mathrm{o}}^{2}\right) ; \theta_{\max }=27.57^{\circ} ; R 1=$ $0.0560, w R 2=0.1280$.

Data for 3: $\mathrm{C}_{77} \mathrm{H}_{51} \mathrm{Cl}_{14} \mathrm{~N}_{4} \mathrm{O}_{2} \mathrm{~S}_{3}, M_{r}=1656.70$; crystals obtained from THF/ $\mathrm{CH}_{2} \mathrm{Cl}_{2}$ /hexane; crystal size $0.40 \times 0.35 \times 0.25 \mathrm{~mm}^{3}$; triclinic, space group $P \overline{1}, a=14.0817(5), b=16.2298(6), \mathrm{c}=18.0591(6) \AA, \alpha=101.473(1)^{\circ}, \beta=$ $111.753(1)^{\circ}, \gamma=90.881(1)^{\circ}, V=3738.7(2) \AA^{3,} Z=2, \rho_{\text {calcd }}=1.472 \mathrm{mg} \mathrm{m}^{-3}$; $\mu=0.650 \mathrm{~mm}^{-1}, F(000)=1686 ; 49599$ measured reflections collected; 17163 observed reflections. $\left(F_{\mathrm{o}}^{2}>2 \rho F_{\mathrm{o}}^{2}\right) ; \theta_{\max }=27.50^{\circ} ; \quad R 1=0.0769$, $w R 2=0.2229$.

\section{Acknowledgements}

This work is supported by National Science Council (Taiwan). We thank Mrs. Mei-Yueh Chien (Instrument Center, NCHU) for the measurements of NMR spectra.

[1] J. L. Sessler, A. Gebauer, E. Vogel, The Porphyrin Handbook, Vol. 2 (Eds.: K. M. Kadish, K. M. Smith, R. Guilard), Academic Press, San Diego, 1999, Chapter 8.
[2] A. K. Burrel, J. L. Sessler, M. J. Cyr, E. McGhee, J. A. Ibers, Angew. Chem. 1991, 103, 83-85; Angew. Chem. Int. Ed. Eng. 1991, 30, 91 - 93.

[3] V. Karl, H. Furuta, K. Shreder, V. Lynch, J. L. Sessler, J. Am. Chem. Soc. 1996, 118, $1595-1607$.

[4] J. L. Sessler, P. I. Sansom, V. Karl, D. O'Conner, B. L. Iverson, J. Am. Chem. Soc. 1996, 118, 12322-12330.

[5] J. L. Sessler J. M. Davis, Acc. Chem. Res. 2001, 34, 989-997.

[6] J. L. Sessler, G. Hemmi, T. D. Mody, T. Murai, A. Burrell, S. W. Young, Acc. Chem. Res. 1994, 27, 43-50.

[7] J. L. Sessler, T. Murai, G. Hemmi, Inorg. Chem. 1989, 28, 3390-3393.

[8] S. J. Narayanan, B. Sridevi, T. K. Chandrashekar, A. Vij, R. Roy, J. Am. Chem. Soc. 1999, 121, 9053-9068.

[9] P. J. Chmielewski, L. Latos-Grażyñski, M. M. Olmstead, A. L. Balch, Chem. Eur. J. 1997, 3, 268-278.

[10] A. Ulman, J. Manassen, J. Am. Chem. Soc. 1975, 97, 6540-6544.

[11] A. Ulman, J. Manassen, F. Frolow, D. Rabinovich, Tetrahedron Lett. 1978, $167-170$.

[12] A. Ulman, J. Manassen, F. Frolow, D. Rabinovich, Tetrahedron Lett. 1978, $1885-1186$.

[13] N. Sprutta, L. Latos-Grażyñski, Chem. Eur. J. 2001, 7, 5099-5112.

[14] J.-P. Jong, M.-Y. Ho, C.-H. Hung, G.-H. Lee, S.-M. Peng, unpublished results.

[15] L. Latos-Grażyñski, J. Wojaczynski, R. Koerner, J. J. Johnson, A. L. Balch, Inorg. Chem. 2001, 40, 4971-4977.

[16] A. K. Burrell, M. J. Cyr, V. Lynch, J. L. Sessler, J. Chem. Soc. Chem. Commun. 1991, 1710-1713.

[17] M. Stepien, L. Latos-Grażyñski, Chem. Eur. J. 2001, 7, 5113-5117.

[18] H. Furuta, T. Ishizuka, A. Osuka, T. Ogawa, J. Am. Chem. Soc. 1999, 121, $2945-2946$; H. Furuta, T. Ishizuka, A. Osuka, T. Ogawa, J. Am. Chem. Soc. 2000, 122, 5748-5757.

[19] J.-Y. Shin, H. Furuta, A. Osuka, Angew. Chem. 2001, 113, 639-641; Angew. Chem. Int. Ed. 2001, 40, 619-621.

[20] K. M. Kadish, C. Araullo-McAdams, B. C. Han, M. M. Franzen, J. Am. Chem. Soc. 1990, 112, 8364-8368.

[21] P. J. Chmielewski, L. Latos-Grażyñski, K. Rachlewicz, Chem. Eur. J. 1995, $1,68-73$.

[22] G. Märkl, Th. Knott, P. Kreitmeier, T. Burgemeister, F. Kastner, Tetrahedron, 1996, 52, 11763-11782.

[23] Organocopper Reagents: A Practical Approach (Ed.: R. J. K. Taylor), Oxford University Press, 1995.

[24] J. A. Joule, K. Mills, G. F. Smith, Heterocyclic Chemistry, 3rd ed., Chapman \& Hall, London, 1995, pp. 229-277.

[25] a) S. K. Arora, M. B. Cox, D. Arjunan, D.; J. Med. Chem. 1990, 33 $3000-3008$; b) K. Shirahata, N. Hirayama, J. Am. Chem. Soc. 1983 , $105,7199-7200$.

[26] W. L. F. Armarego, D. D. Perrin, Purification of Laboratory Chemicals, 4th ed., Bath Press, Bath (UK), 1996.

[27] a) A. Bell, R. A. Walton, D. A. Edwards, M. A. Poulter, Inorg. Chim Acta. 1985, 104, 171-178; b) G. J. Kubas, B. Monzyk, A. L. Crurnbliss Inorg. Synth. 1979, 19, 90-92.

[28] G. M. Sheldrick, SHELXTL, Program for Crystal Structure Determination, Siemens Analytical X-ray Instruments, Madison, WI, 1994

[29] G. M. Sheldrick, SADABS, Siemens Area Detector Absorption Correction Program, University of Göttingen (Germany), 1996.

Received: April 22, 2002 [F4044] 